\title{
От идеи до продвижения: инструменты маркетинга гражданской продукции
}

\author{
А. Крылова
}

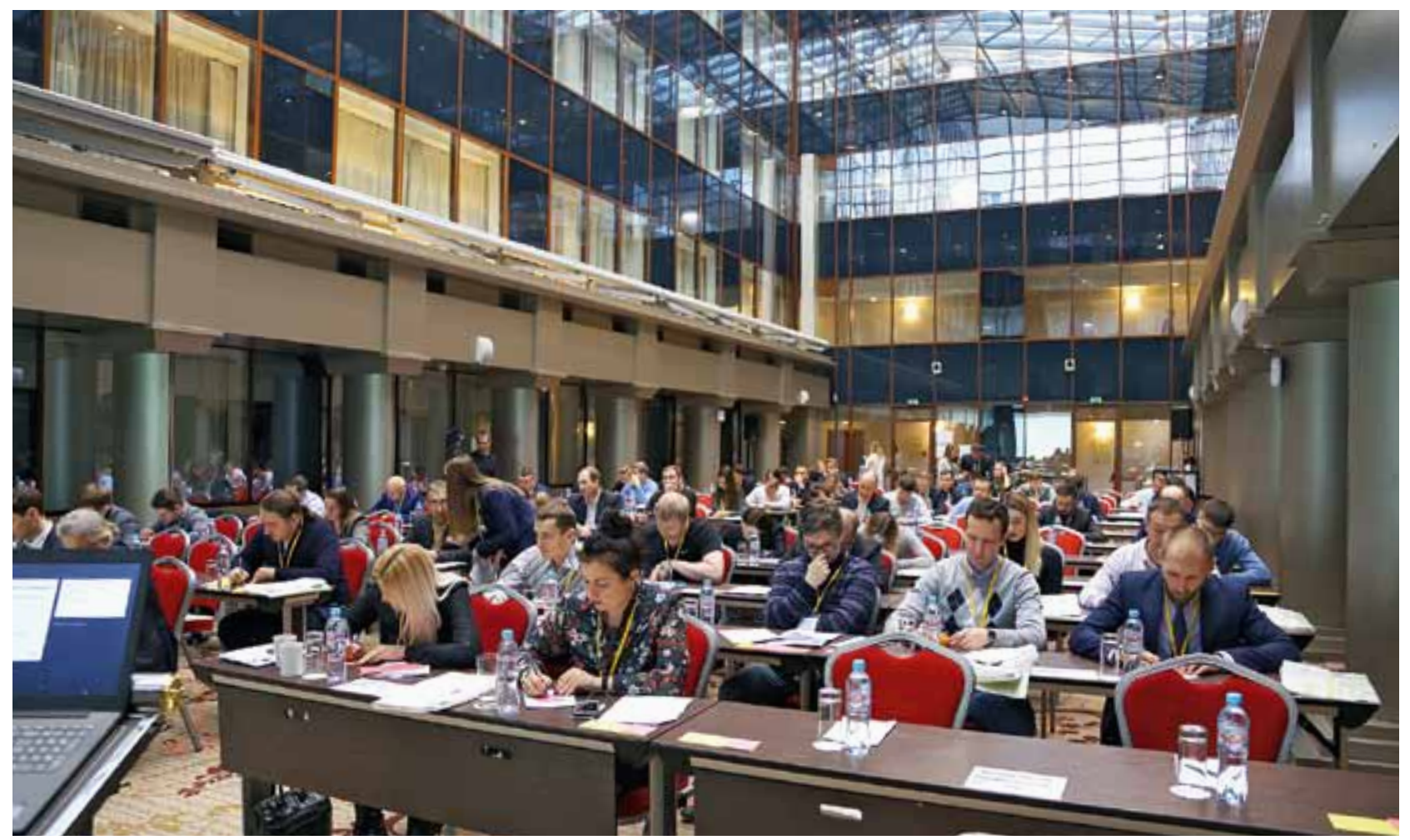

6 декабря 2019 года в Москве состоялась очередная сессия Сообщества по развитию гражданской продукции Академии Ростеха. Ее тема была обозначена как "Маркетинг: идея, продукт, продвижение». В качестве партнера мероприятия выступила Группа компаний Остек. Эксперты в области исследования рынка, брендинга, продвижения продукции поделись с Сообществом своими знаниями и опытом, которые могут быть полезны, в том числе для решения задачи выхода предприятий ОПК на новый для них рынок гражданской продукции.

оздание инновационныхпродуктов гражданского назначения с высокой интеллектуальной составляющей, конкурентоспособных на быстрорастущих мировых рынках - задача, которую руководство Госкорпорации «Ростех» поставило перед входящими в ее состав предприятиями.

Для ее решения в 2018 году в рамках Академии Ростеха была запущена программа "Вектор", которая направлена на поиск технологических лидеров, работающих в периметре Госкорпорации, готовых не просто предложить идею создания высокотехнологичного гражданского продукта, но и активно работать в этом направлении.
Программа "Вектор" действует в течение двух лет, за это время на базе Академии было сформировано и успешно работает Сообщество по развитию гражданской продукции. В рамках Сообщества проходят встречи, лекции и сессии, где рассматриваются актуальные для направления темы.

Темой заключительной в 2019 году встречи стал маркетинг и его инструменты, ведь важно не просто создать высокотехнологичный продукт, необходимо знать и уметь выстраивать взаимоотношения с заказчиками, понимать, как формировать бренд и продвигать его на рынке. 
Модератор сессии, Антон Большаков, директор по маркетингу ГК Остек, сформулировал ее задачу так: "Обсудить, как маркетинг может стать связующим звеном между стратегическими планами предприятий и реальными ожиданиями рынка».

\section{НАДЕЖНЫЙ ФУНДАМЕНТ ДЛЯ УПРАВЛЕНЧЕСКИХ РЕШЕНИЙ}

Разработка концепции любого нового продукта начинается с выдвижения гипотез, каждая из которых требует подтверждения. Для этого служит такой инструмент, как маркетинговые исследования.

О практике проведения таковых в АО «Росэлектроника» (методах сбора и анализа информации, ее источниках и основных этапах) участникам сессии рассказал представитель управления маркетинга этого холдинга Артур Пищик, за плечами которого более 100 проектов в области анализа рынков, технологий и стратегий в интересах крупных государственных и частных компаний.

По его словам, в АО «Росэлектроника» маркетинговые исследования проводятся для поиска перспективных направлений и рыночных ниш, привлечения инвесторов, разработки новых продуктов и построения системы их продаж, а также управления их полным жизненным циклом.

А. Пищик определил маркетинговые исследования как структурированно отработанный анализ информации о рынке и о конкурентах в целях уменьшения неопределенности при принятии управленческих решений и обеспечения информацией различных подразделений организации.

В качестве примера он привел аналитический отчет «Рынок газоанализаторов в России в 2015-2017 годах, прогноз до 2022 года», подготовленный в 2018 году. Используя метод кабинетного исследования и такие источники информации, как базы данных ФТС России, корпоративные сайты, а также портал госзакупок, аналитикам управления маркетинга удалось получить результаты, которые мотивировали руководство АО «Росэлектроника" принять решение о разработке взрывозащищенного газоанализатора для контроля атмосферы на промышленных объектах, где возможно образование взрывоопасных газовых смесей.

Процесс проведения маркетингового исследования многоэтапный. На первом этапе определяются проблемы и формулируются цели маркетингового исследования, на основании которыхготовится ТЗ для аналитиков, или бриф. На втором - разрабатывается план: определяются методы исследования, тип требуемой информации и ее источники, оговариваются способы сбора данных и проектируются формы для такого сбора. Сбор данных и их анализ проводятся на третьем этапе, а на четвертом - результаты анализа оцениваются, интерпретируются и представляются заказчику в виде презентации с диаграммами, таблицами и графиками.

Для сбора данных и проведения маркетинговых исследований аналитики АО «Росэлектроника» обычно используют открытые источники, к примеру, сайты компаний, их отчетность, а также различные базы и информационные сервисы, из которых получают информацию о компаниях, структуре их собственности и составе акционеров, таможенную статистику, включая таможенные декларации участников ВЭД.

«Основные навыки, которые обязательно должны быть у аналитика, - умение находить информацию и правильно, точно ее обрабатывать", - констатировал А. Пищик. По его опыту, при помощи наставников такие навыки приобретаются за 6-12 месяцев.

\section{СВОИМИ СИЛАМИ ИЛИ ПРИ УЧАСТИИ АГЕНТСТВА?}

Применительно к маркетинговым исследованиям каждая компания отвечает на этот вопрос по-своему. Антон Большаков в своем выступлении сфокусировался на случаях, в которых сотрудничество с маркетинговым агентством бывает полезным.

По его убеждению, привлекать такого внешнего партнера стоит к исследованию новых рынков и при рассмотрении специализированных тематик. Оправдано оно также в условиях сжатых сроков. Кроме того, маркетинговое агентство можно и нужно подключать на этапах, которые или требуют больших трудозатрат (сбор данных для количественных исследований) или определенных компетенций и владения той или иной методологией (например, работа с фокус-группами).

При выборе маркетингового агентства для решения тех или иных задач А. Большаков посоветовал обращать внимание не только на цены услуг (разброс стоимости одного и того же объема работ на этом рынке может отличаться на порядки), но и на специализацию исследовательской компании. Полезно также попросить потенциального партнера предоставить примеры аналогичных отчетов, подготовленных для других заказчиков.

По мнению докладчика, для верификации результатов работы подрядчика наиболее эффективны такие методы, как выборочная проверка исходных данных, консультации с экспертами, сравнение предоставленных данных с имеющимися, проверка интерпретации данных, представленных в исследовании.

В идеале для проведения маркетингового исследования требуется формирование проектной команды, включающей в себя маркетологов компании, экспертов и представителей агентства, постоянно взаимодействующих между собой и информирующих заказчика обо всех, даже промежуточных, результатах. 


\section{ГИБКИЙ ПОДХОД ПРЕДПОЧТИТЕЛЕН}

Создание нового продукта всегда неразрывно связано с управлением проектами. О разработке площадки «ЭКБ МАРКЕТ», проведенной проектной командой под руководством ФГУП «МНИИРИП» в интересах Департамента радиоэлектронной промышленности Минпромторга России, рассказал вячеслав Кузнецов, руководитель специальных проектов ГК Остек.

Идея - разработать программный продукт, упрощающий применение отечественной ЭКБ, своего рода аналог Яндекс. Маркета, возникла у директора ФГУП «МНИИРИП» и получила поддержку в коллективе.

Было предложено подойти к этой задаче, как к проекту, и применить гибкий подход: за месяц разработать прототип такой системы, собрать информацию об отношении к ней первых пользователей, а заодно и проверить гипотезу о том, что сама идея такого электронного сервиса правильная.

Гибкий подход предполагает разбивку проекта по созданию продукта на функциональные зоны, затем функционал каждой из них проходит стадии разработки, тестирования и внедрения. Такое деление на этапы, или спринты, позволяет оперативно получать обратную связь от пользователей и достигать наилучших результатов.

Заказчика это предложение устроило, и проект был запущен. Начался он с создания проектной команды - выделения ролей руководителя проекта и владельца продукта. Помимо них, в нее вошли бизнес-аналитики, маркетологи, разработчики ПО и технические эксперты. В роли последних выступили самые активные потенциальные пользователи продукта. Они привлекались к проверке гипотез. Также их мнение учитывалось при уточнении постановки задач и при разработке прототипа.

Роль владельца продукта заключалась в том, чтобы активно взаимодействовать с потенциальными потребителями и «продавать" им все наработки. Руководитель проекта координировал действия членов команды.

Применение общедоступных средств коммуникации позволило организовать совместную работу членов команды в соответствии с требованиями к управлению проектами. Так, для ведения реестра заинтересованных лиц использовалась адресная книга корпоративной электронной почты, обсуждение рабочих задач велось в группах по компетенциям, созданных в мессенджере, а для ведения актуального списка приоритетных задач проекта был задействован популярный бесплатный сервис Trello.

По окончании первого спринта заказчику были продемонстрированы представления товаров в программном продукте с возможностью их сравнения, интеллект-карта развития его функционала на два года вперед, а также планы работы для ближайших спринтов. Результаты и заказчику, и пользователям понравились. У них появилось понимание, что подобные задачи нужно решать в ходе проектной деятельности. А главное, сложилась грамотная, эффективная команда, способная продолжать развивать программный продукт дальше.

Результат второго спринта - проверка работающего прототипа техническими экспертами. После третьего спринта доступ к системе «ЭКБ МАРКЕТ» был открыт пользователям. На сегодняшний день позади уже 12 спринтов, с каждым из которых потребитель получал новую ценность.

Подводя черту под сказанным, В. Кузнецов отметил, что проектный подход - не волшебная таблетка, но при правильном применении он помогает в разработке нового продукта, в том числе и в госсекторе.

\section{ИНТЕРНЕТ-МАРКЕТИНГ, ЗММ, ВЫСТАВКИ: РЕКОМЕНДАЦИИ ПО ПРИМЕНЕНИЮ}

Так ли подходит среда Интернета для продвижения высокотехнологичной продукции гражданского назначения, на разработку которой сегодня нацелены ведущие предприятия? Есть несколько проблем, не позволяющих дать на этот вопрос однозначно положительный ответ.

С них и начал свой доклад Николай Батраков, начальник группы интернет-проектов ГК Остек. Во-первых, для производственных компаний нет готовых рецептов продвижения своей продукции в цифровой среде, их приходится искать методом проб и ошибок; во-вторых, успех продукта на В2В-рынке во многом определяют прямые продажи. Кроме того, цикл продаж высокотехнологичной продукции длинный: от первого знакомства с продуктом до заключения сделки может пройти больше года. К тому же рекламу в Интернете сложно таргетировать, поскольку специалисты, которые собирают информацию о продукте, часто не являются лицами, принимающими решения. В совокупности все эти факторы влияют на стоимость интернет-привлечения клиентов: на корпоративном рынке она выше, чем на потребительском.

Между тем, в арсенале интернет-маркетологов есть немало действенных digital-инструментов, полезных на всех этапах разработки гражданской продукции. Они существенно облегчают проверку идеи продукта, формирование на его основе уникального торгового предложения и его продвижение в заданном сегменте рынка.

Так, для сбора данных об аудитории он рекомендовал использовать аналитические онлайн-сервисы яндекс. Wordstat и Google Trends (последний особенно актуален, если предполагается разрабатывать продукт для зарубежных рынков). Также полезными могут быть аналитика Mail.ru и Facebook. А с помощью платных инструментов Serpstat и SimilarWeb можно извлечь много важной информации о конкурентах, их тактике и стратегии.

В итоге еще на этапе проработки идеи средства интернет-маркетинга позволяют довольно точно оценить востребованность создаваемого продукта, выявить его 
потенциальных потребителей, понять, с какими компаниями придется конкурировать и какую долю рынка у них можно будет отвоевать.

Для превращения нового продукта в уникальное торговое предложение маркетологи ГК Остек активно используют посадочные страницы, или лендинги. Используя популярные конструкторы (Tilda, Platforma LP, Битрикс.24, LP Generator и некоторые другие), можно самостоятельно с небольшими затратами и быстро развернуть одностраничный сайт, посвященный ключевым преимуществам нового продукта, для лидогенерации или альфа- и бетатестирования его концепции.

А максимальный эффект для информирования потребителей об уникальных торговых преимуществах нового продукта достигается путем интеграции лендинга в общую структуру корпоративного сайта. Она, кстати, должна обязательно быть адаптирована к просмотру с мобильных устройств. Такая оптимизация позволяет повысить посещаемость и в конечном счете помогает найти новых клиентов.

Для продвижения продукта на рынке В2В, по мнению спикера, подходят такие маркетинговые инструменты, как поисковая оптимизация, SEO, контекстная реклама, а также рассылки, сервисы личного кабинета, интернетпомощник.

Отдельный доклад на сессии был посвящен контентмаркетингу и коммуникациям в социальных сетях. По опыту ГК Остек, промышленные предприятия могут с успехом использовать SMM для расширения охвата уникальной аудитории, для живого неформального общения с ней. Страница компании в соцсети идеально подходит для интересных рассказов о новых разработках и о важных событиях в жизни предприятия, для диалога с потенциальными клиентами, для вовлечения их в обсуждение актуальной отраслевой тематики и для выявления их отношения к перспективным продуктам. Отправной точкой для постановки этого маркетингового направления должна стать разработка Стратегии продвижения в соцсетях - документа, определяющего, каким должно быть лицо компании в виртуальном пространстве, а также содержание и тон коммуникаций с пользователями.

Еще более мощный эффект достигается за счет комбинации инструментов интернет-маркетинга и коммуникаций с офлайновыми мероприятиями, например с выставками. Для того чтобы получать максимум от участия в выставках Николай Желясков, начальник группы управления мероприятиями ГК Остек, порекомендовал заранее определить цели, достичь которые важно в ходе мероприятия, донести эти цели до персонала, задействованного в нем, и продумать, как использовать результаты взаимодействия с посетителями стенда в будущем.

\section{СОЗДАТЬ ПРАВИЛЬНЫЙ ОБРАЗ}

Бренд - это образ, который целенаправленно формируется в сознании целевой аудитории, отметил Денис Шлесберг, директор брендингового агентства "Артоника», член Совета Ассоциации брендинговых компаний России (АКБР). Чем сильнее бренд, тем мощнее влияние образа на лояльность потребителей.

В идеале к формированию такого образа производителю продукта стоит привлечь брендинговое агентство. Такое сотрудничество даст взгляд на продукт со стороны, благодаря чему образ получается особенно точным.

Процесс создания бренд-платформы начинается с серьезной работы по анализу самого продукта, его аудитории и конкурентов именно с точки зрения брендинга. Кроме того, для разработки визуальной концепции предметами детального рассмотрения должны стать форматы, средства выражения, визуальная среда и тренды. Одновременно

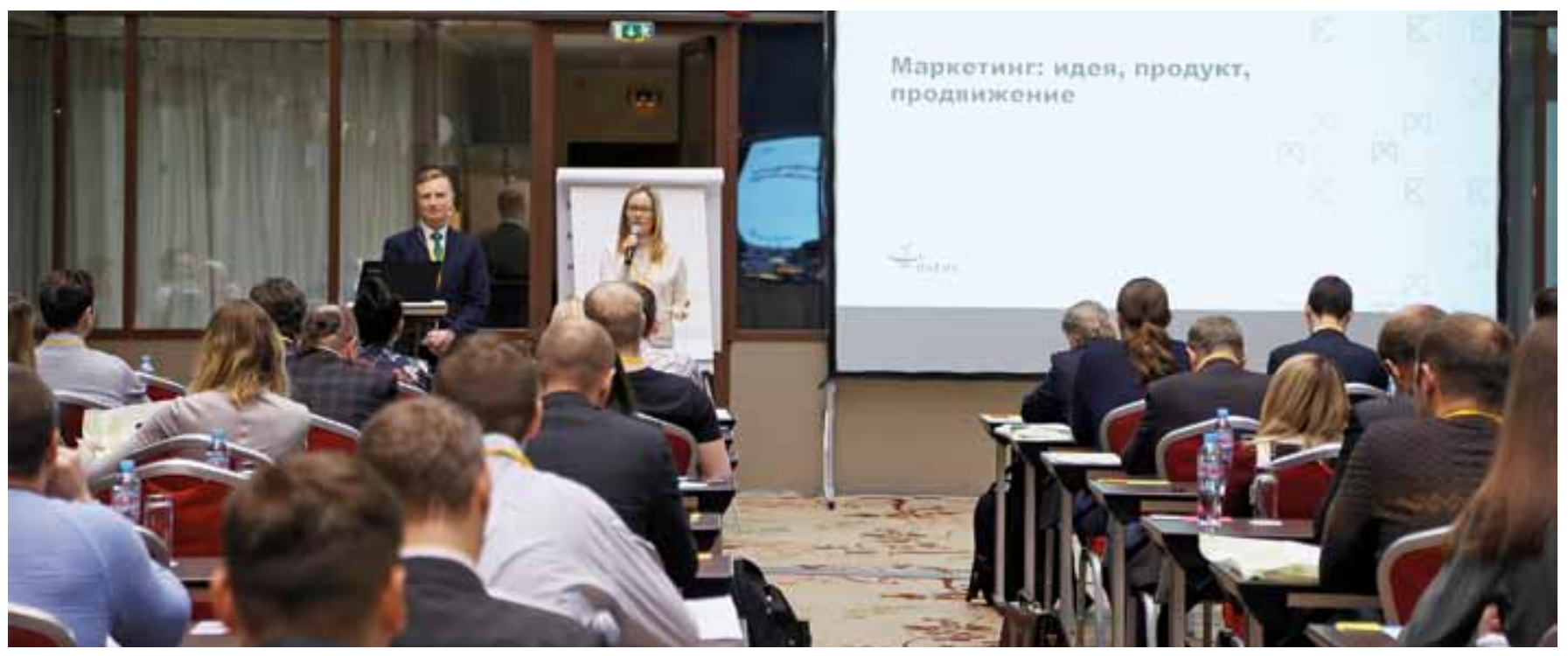


формулируются функциональные требования к бренду и его представлению.

Существуют разные модели бренд-платформ. Докладчик продемонстрировал бренд-платформу «Колесо бренда», представляющую собой круг с двумя контурами. Центральное место в нем занимает идея бренда, выраженная очень коротко. Над ней размещается описание позиционирования бренда, заключенное в одном предложении. Расположенные справа рациональные ценности бренда показывают, чем отождествляемый с ним продукт лучше аналогов. Слева - эмоциональные выгоды, чувства, которые вызывает у потребителя бренд и мотивы, по которым он этот бренд выбирает на ценностном уровне. В верхнем контуре закрепляются ценности, которые производитель продукта разделяет с потребителем. И нижний контур - это черты характера бренда, если представить его человеком.

В качестве примера успешной разработки агентства «Артоника» в области корпоративного брендинга Д. Шлесберг привел бренд, созданный для консорциума, в который решили объединиться два производителя авиакомпонентов для предложения пакетированныхуслуг для авиапроизводителей. Один из них выпускает системы жизнеобеспечения воздушных судов, а второй - винты для самолетов.

Брендинговое агентство «Артоника» разработало брендплатформу и концепцию позиционирования для этой новой холдинговой структуры, названной «Группа Небо». По счастью, слово "Небо» и в русском, и в латинском написании оказалось незанятым, что позволило его зарегистрировать как бренд. По словам Д. Шлесберга, миссия новой структуры была сформулирована как создание и объединение возможностей для взлета. Сочетание романтического контекста, связанного для всех, кто работает в авиационной промышленности со словом “небо», и скупого, лаконичного шрифта сделало бренд запоминающимся.

«Какой стратегии в области брендинга стоит придерживаться при выводе на рынок гражданской продукции предприятиям ОПК, чьи бренды, что называется, на слуху, но ассоциируются с военной техникой?»- спросили мы у Д. Шлесберга в кулуарах сессии.

«Как правило, сильный индустриальный бренд слабо соотносится с потребительским рынком, для которого планируется разработать гражданский продукт, - констатировал он, - поэтому начинать надо с того, чтобы внимательно посмотреть, какие бренды уже на этом рынке присутствуют, как они выражают свои преимущества, и какой образуется в результате контекст, влияющий на восприятие потребителей. И с учетом этого разрабатывать новый продуктовый бренд".

\section{ГДЕ ИСКАТЬ ИДЕИ ДЛЯ ПРОДУКТОВ?}

Олег Ена, руководитель проектного офиса ФГБУ «Федеральный институт промышленной собственности" (ФиПС), видит одним из важнейших источников патентную информацию. В патентной информации детально описаны технологии и способы изготовления продукции, и правильный анализ этой информации позволяет выявить ключевые направления развития современных компаний и понять, чего именно не достает вашему продукту.

Помимо этого, важно, что за патентную информацию российские и зарубежные компании платят деньги. Чем более ценен для компании продукт, тем больше компания вкладывается в его патентную охрану. Затраты компании на патентование одного конкретного продукта могут достигать сотен тысяч долларов. Анализ таких ценных решений также может помочь с поиском собственных идей для развития.

Сегодня в мире более 150 млн патентов, и содержащуюся в них информацию можно анализировать с разных точек зрения. Анализ тематики, областей применения и географии патентования крупных международных компаний позволяет выявить бизнес-намерения и стратегические приоритеты ведущих отраслевых игроков, чтобы затем с учетом этой информации скорректировать существующую стратегию технологического развития или разработать новую.

В распоряжении специалистов из проектного офиса ФИПС сегодня находятся семь самых известных в мире систем патентной аналитики. Выбрав из каждой системы наиболее ценные функции, они получают возможность сформировать конфигурацию аналитики, в максимальной степени отвечающей задачам управления технологиями крупной промышленной компании

Кооперация российских разработчиков с организациями, специализирующимися на анализе патентной информации, по убеждению О. Ена, очень ценна для решения задач диверсификации ОПК по трем ключевым позициям:

- поиск новых областей применения продукции ОПК;

- поиск новой продукции, которую можно производить на оборудовании ОПК;

- анализ востребованности отдельных функций продукции ОПК.

Подводя итоги, А. Большаков отметил: «Ни профессиональный опыт, ни высокие конструкторские компетенции не позволят гарантированно создавать массово востребованные продукты, если они разрабатываются в отрыве от изучения потребностей клиентов и рынка в целом".

По его словам, вера в сильные инженерные компетенции, позволяющие создавать продукты без детального понимания потребностей и мотивов потребителей, без оценки их готовности покупать, приводит к отсутствию результата.

С этими рекомендациями согласились и участники сессии Сообщества по развитию гражданской продукции Академии Ростеха, отметив в своих отзывах, что узнали «много практических вещей для предприятий, нацеленных на диверсификацию». 


\section{Что скрывается за передовым производством?}

\section{Живой процесс}

